\title{
HUBUNGAN KEHAMILAN PRANIKAH DENGAN KEJADIAN ABORTUS PMB BIDAN E KOTA BANDUNG
}

\author{
Dian Purnama Sari ${ }^{1 *}$, Nurlelah ApriliaS. Iskandar ${ }^{1}$ \\ ${ }^{1}$ Sekolah Tinggi Ilmu Kesehatan Dharma Husada, Bandung, Indonesia \\ *Korespondensi : dians1552@gmail.com
}

\begin{abstract}
Backgorund: Abortion is one of the direct causes of maternal mortality. The highest incidence of abortion in West Java Province was 22.90\%. The incidence of abortion in PMB Midwife E has increased, while the teenage pregnancy rate has decreased. To determine the relationship between teenage pregnancy and the incidence of abortion at PMB Midwife E in 2019. Method: The research design used is case control. The population in this study were all pregnant women in PMB Midwife E in 2019. The total sample was 104 pregnant women consisting of 52 cases and 52 controls who met the inclusion and exclusion criteria. The data obtained were taken from the medical records of pregnant women from January-December 2019. The sampling technique was simple random sampling. Data analysis using Chi-Square. Result: bivariate analysis showed that there was a relationship between teenage pregnancy and the incidence of abortion $(p=0.031)$, there was a correlation between parity and the incidence of abortion $(p=0.010)$, there was a relationship between work and the incidence of abortion ( $p=0.006)$, there was no relationship between education and the incidence of abortion. abortion ( $p=0.324)$. Conclution: There is a relationship between teenage pregnancy, parity, and occupation with the incidence of abortion. There is no relationship between education and the incidence of abortion. (Background, Methods, Results, Conclusion).
\end{abstract}

Keywords: Abortion, pregnancy, premarital, teenage

\begin{abstract}
ABSTRAK
Abortus merupakan salah satu penyebab langsung angka kematian ibu. Kejadian abortus di Provinsi Jawa Barat tertinggi 22.90\%. Kejadian abortus di PMB Bidan E mengalami peningkatan, sedangkan angka kehamilan remaja mengalami penurunan. Mengetahui hubungan kehamilan remaja dengan kejadian abortus di PMB Bidan E tahun 2019. Desain penelitian yang digunakan adalah Case control. Populasi dalam penelitian ini adalah seluruh ibu hamil di PMB Bidan E tahun 2020. Total sampel adalah $104 \mathrm{ibu}$ hamil terdiri dari 52 kasus dan 52 kontrol yang memenuhi kriteria inklusi dan eksklusi. Data diperoleh diambil dari rekam medik ibu hamil dari bulan Januari-Desember tahun 2020. Teknik pengambilan sampel dengan simple random sampling. Analisis data menggunakan Chi-Square.Hasil analisis bivariat menunjukkan ada hubungan kehamilan remaja dengan kejadian abortus $(\mathrm{p}=0.031)$, ada hubungan paritas dengan kejadian abortus $(\mathrm{p}=0.010)$, ada hubungan pekerjaan dengan kejadian abortus $(\mathrm{p}=0.006)$, tidak ada hubungan pendidikan dengan kejadian abortus $(\mathrm{p}=0.324)$.
\end{abstract}


Ada hubungan kehamilan remaja, paritas, dan pekerjaan dengan kejadian abortus. Tidak ada hubungan pendidikan dengan kejadian abortus.

Kata kunci : Abortus, kehamilan, pranikah, remaja

\section{PENDAHULUAN}

Angka kematian ibu masih sangat tinggi. Sekitar 99\% kematian maternal terjadi di negara-negara berkembang. Angka kematian ini masih menjadi masalah di berbagai negara berkembang termasuk Indonesia. 1 Salah satu penyebab langsung AKI yaitu abortus.3 WHO menetapkan bahwa abortus termasuk dalam masalah kesehatan reproduksi yang perlu mendapatkan perhatian dan merupakan penyebab penderitaan wanita di seluruh dunia.

Faktor risiko yang menyebabkan abortus adalah faktor janin, faktor ibu dan faktor ayah. Faktor risiko dari janin meliputi kelainan perkembangan zigot, kelainan jumlah kromosom, kelainan struktur kromosom, kelainan plasenta. Sedangkan faktor risiko dari ibu meliputi konsumsi alkohol, kelainan imunologi, penyakit ibu seperti anemia, hipertensi, dan diabetes melitus, kelainan rahim, umur, paritas, jarak kehamilan, riwayat abortus, dan pekerjaan. Faktor risiko dari ayah meliputi kelainan kromosom sperma dan umur. Kehamilan pada remaja menjadi salah satu faktor risiko terjadinya abortus. Kehamilan yang terjadi pada usia remaja rentan mengalami gangguan kehamilan dan permasalahan lain yang berhubungan dengan kehamilan di usia muda. Kejadian abortus di Kota Bandung pada tahun 2015 sebesar 8.14\% kasus, tahun 2016 menurun menjadi 7.95\% kasus, dan pada tahun 2019 meningkat menjadi $22.90 \%$ kasus. Kehamilan remaja di Kota Bandung pada tahun 2015 sebesar 6.47\% kasus, tahun 2016 meningkat menjadi 9.19\% kasus, dan pada tahun 2019 menurun menjadi 7.46\% kasus. Data tersebut menunjukkan bahwa kejadian abortus dari tahun 2016- 2019 mengalami peningkatan, sedangkan ditahun yang sama angka kehamilan remaja mengalami penurunan. 


\section{METODE}

ini adalah seluruh ibu hamil di PMB Bidan E tahun 2020 pada bulan Mei 2021. Total sampel adalah 104 ibu hamil terdiri dari 52 kasus dan 52 kontrol yang memenuhi kriteria inklusi dan eksklusi. Data diperoleh diambil dari rekam medik ibu hamil dari bulan Januari-Desember tahun 2020. Teknik pengambilan sampel dengan simple random sampling.

\section{HASIL}

Abortus didefinisikan sebagai ancaman atau pengeluaran hasil konsepsi sebelum janin dapat hidup diluar kandungan. Sebagai batasan ialah kehamilan kurang dari 20 minggu atau berat janin kurang dari 500 gram.

Tabel 1 Karakteristik Ibu Hamil Yang Mengalami Abortus

\begin{tabular}{lcccc} 
& \multicolumn{2}{c}{ Abortus } & Tidak Abortus \\
\hline \multicolumn{1}{c}{ Karakteristik } & $\mathrm{n}$ & $\%$ & $\mathrm{n}$ & $\%$ \\
\hline Kehamilan Remaja & & & & \\
\hline a. Remaja $(<20$ tahun $)$ & 16 & 30.8 & 6 & 11.5 \\
\hline b. Bukan Remaja $(\geq 20$ tahun $)$ & 36 & 69.2 & 46 & 88.5 \\
\hline Paritas & & & & \\
\hline a. Berisiko $(\leq 1$ dan $>4)$ & 29 & 55.8 & 15 & 28.8 \\
\hline b. Tidak Berisiko $(2-4)$ & 23 & 44.2 & 37 & 71.2 \\
\hline Pendidikan & & & & \\
\hline a. Rendah & 32 & 61.5 & 26 & 50.0 \\
\hline b. Tinggi & 20 & 38.5 & 26 & 50.0 \\
\hline Pekerjaan & & & \\
\hline a. Bekerja & 23 & 44.2 & 9 & 17.3 \\
\hline b. Tidak Bekerja & 29 & 55.8 & 43 & 82.7 \\
\hline Jumlah & 52 & 100 & 52 & 100 \\
\hline Sumber : Data Sekunder PMB Bidan E Tahun 2020
\end{tabular}

Berdasarkan hasil penelitian diketahui bahwa karakteristik ibu hamil yang mengalami abortus di PMB Bidan E yaitu lebih banyak pada ibu yang berusia $<20$ tahun (remaja) (30.8\%), paritas berisiko (55.8\%), ibu yang memiliki pendidikan rendah (61.5\%), dan ibu yang bekerja (44.2\%). 
Tabel 2. Tabel Silang Pekerjaan dengan Kejadian Abortus di PMB Bidan E Tahun 2020

\begin{tabular}{lccccc}
\hline \multirow{2}{*}{ Pekerjaan } & \multicolumn{5}{c}{ Kejadian Abortus } \\
\cline { 2 - 7 } & \multicolumn{3}{c}{ Ya } & \multicolumn{4}{c}{ Tidak } & p-value \\
& $\mathrm{n}$ & $\%$ & $\mathrm{n}$ & $\%$ & \\
\hline Bekerja & 23 & 44.2 & 9 & 17.3 & 0.006 \\
Tidak Bekerja & 29 & 55.8 & 43 & 82.7 & \\
\hline Jumlah & 52 & 100 & 52 & 100 & \\
\hline Sumber : Data Sekunder PMB Bidan E Tahun 2020
\end{tabular}

Berdasarkan hasil uji chi-square menunjukkan nilai p-value $0.031(<0.05)$ yang berarti terdapat hubungan antara kehamilan remaja dengan abortus.

\section{DISKUSI}

Pernikahan remaja, usia kehamilan yang terlalu muda merupakan risiko dari abortus. Ibu hamil yang berusia $<20$ tahun dapat merugikan kesehatan ibu maupun pertumbuhan dan perkembangan janin. Secara biologis perkembangan alat-alat reproduksinya masih dalam proses kematangan belum sepenuhnya optimal sehingga belum siap untuk menerima kehamilan. Kondisi panggul yang masih sempit, otot rahim yang belum terbentuk sempurna, pembuluh darah yang mensuplai endometrium belum banyak terbentuk yang disebabkan karena masih dalam masa pertumbuhan sehingga bila terjadi kehamilan dan persalinan akan lebih mudah mengalami komplikasi diantaranya abortus. Keadaan tersebut akan makin menyulitkan bila ditambah dengan tekanan (stres) psikologi, sosial, ekonomi, sehingga memudahkan terjadinya abortus.

Pada usia $<20$ tahun secara psikologis kondisi mental belum siap menghadapi kehamilan dan menjalankan peran sebagai ibu sehingga menimbulkan stres. Stres fisik atau mental ini dapat menyebabkan peningkatan sekresi hormon Adrenokortikotropik $(\mathrm{ACTH})$ dengan segera dan bermakna oleh kelenjar hipofisis anterior dan akibatnya sekresi kortisol juga akan sangat meningkat. Kadar katekolamin dalam darah juga meningkat sehingga menyebabkan fungsi plasenta menurun dan progesteron juga menurun yang akhirnya dapat menyebabkan terjadinya abortus.

Hasil penelitian ini sesuai dengan penelitian sebelumnya. Berdasarkan hasil penelitian Ricika menunjukkan bahwa ada hubungan antara umur dengan kejadian abortus pada ibu primigravida dengan $\mathrm{p}$-value $=0.041(<0.05)$ dan $\mathrm{OR}=4.333(\mathrm{CI} 95 \% 1.203$ $15.605)$ yang artinya ibu primigravida dengan umur $<20$ tahun memberi peluang 4.333 kali untuk terjadinya abortus dibanding dengan ibu dengan umur $\geq 20$ tahun. Menurut 
hasil penelitian Maliana menunjukkan bahwa ada hubungan antara umur dengan kejadian abortus dengan $\mathrm{p}$-value $=0.011 \quad(<0.05)$. Penelitian Maliana juga membuktikan bahwa faktor risiko paling dominan sebagai penyebab abortus dari hasil uji statistik multivariat yaitu umur dengan nilai OR tertinggi yaitu sebesar 1.985 (95\% CI 1.218- 3.236), ibu dengan umur berisiko ( $<20$ atau $>35$ tahun) 2 kali lebih tinggi terjadi abortus dibandingkan ibu dengan umur tidak berisiko (20-35 tahun).

\section{SIMPULAN}

Berdasarkan hasil penelitian diatas, diperoleh kesimpulan bahwa terdapat hubungan paritas dengan kejadian abortus dan terdapat hubungan kehamilan remaja dengan kejadian abortus dengan proporsi ibu hamil yang mengalami abortus lebih banyak terjadi pada ibu yang berusia $<20$ tahun (remaja), paritas berisiko, ibu yang memiliki pendidikan rendah, dan ibu yang bekerja, proporsi kehamilan remaja pada ibu yang abortus lebih tinggi dibandingkan dengan ibu yang tidak abortus, serta tidak hubungan pendidikan dengan kejadian abortus.

\section{DAFTAR PUSTAKA}

A. J. Managing the pain of primary and secondary dysmenorrhoea. Nurs Times $\mathrm{J}$. 2004;100(10)

Anggidian MP. Pengaruh Lama Siklus Menstruasi Dengan Kadar Glukosa Darah Sewaktu Pada Mahasiswi Fakultas Kedokteran Universitas Lampung Angkatan 2013 Di Bandar Lampung Tahun 2014. 2015.

Carolyn. Ultimate Sports Therapy's Carolyn Zepf shows how to do a Pelvic Rock Exercise. ultimatesportstherapy. 2010.

Edmonds WA, Kennedy TD. An applied reference guide to research designs. Fargostein L, editor. Los Angeles: SAGE; 2019.

Hanjani SR. Pengaruh Pelvic Rocking Terhadap Pengurangan Nyeri Pinggang Persalinan Kala 1 dan Lama Waktu Persalinan Kala II di RSU PKU. J ILMU Kesehat. 2013;2(2):41-55.

Julie B, Stephen B. exercise for dysmenorrhoea. Cochrane Database Syst Rev. 2010;(2). 
Jyoti K, Kaur NKMS, Sarbjot. A Study To Asses The Effectiveness Of Pelvic Rocking Exercise On Dysmenorhea Among Adolescent Girls. Punjab. 2015;431-4.

Larasati T, Alatas F. Dismenore Primer dan Faktor Risiko Dismenore Primer pada Remaja. Mahasiswa Pendidikan Dokter, Fakultas Kedokteran, Universitas Lampung. Majority. 2016;5(3).

N R, MH A-S. Prevalence of menstrual problems and their association with psychological stress in young female students studying health sciences. Saudi Med J. 2018;39(1):67-73.

Narayan K. Puberty Rituals, Reproductive Knowledge and Health of Adolescent Schoolgirls in South India. Asia Pacific Popul J. 2011;16(2):224-36.

Noor. Merawat dan Menjaga Kesehatan Seksual Wanita. Bandung: Grafindo; 2012.

Ratnasari NN, Pertiwi S, Khairiyah II. Pengaruh Pelvic Rocking Exercise Terhadap Nyeri The Effect Of Pelvic Rocking Exercise Toward Primary Dysmenorhea Pain Junior High School Grade 8. Midwife J. 2018;4(02):48-55.

Suhartono A. Hubungan Antara Olahraga Aerobik dengan Penurunan Derajat Dismenore Pada Siswi SMA Negeri 5 Malang. 2011.

Suparto A. Efektifitas Senam Dismenore dalam Mengurangi Nyeri Dismenore pada Remaja Putri. J Phederal. 2011;4(1).

Ummi. Asuhan Kebidanan pada Kehamian Fisiologis. Jakarta: Salemba Medika; 2010.

Wiknjosastro H. Ilmu Kebidanan. Jakarta: Yayasan Bina Pustaka Sarwono Prawieoharjo; 2007.

Zaky, Hassan, Nevertity. Effect Of Pelvic Rocking Exercise Using Sitting Position On Birth Ball During The First Stage Of Labor On Its Progress. OSR-JNHS. 2016;5(4). 